\title{
Petroleum sludge treatment and disposal: A review
}

\author{
Olufemi Adebayo Johnson ${ }^{1^{\dagger}}$, Augustine Chioma Affam ${ }^{2}$ \\ ${ }^{1}$ School of Energy, Ceoscience, Infrastructure and Society, Heriot-Watt University Malaysia, No. 1, Jalan Venna P5/2, Precinct 5, 62200 Putrajaya, Malaysia \\ ${ }^{2}$ Civil Engineering Department, University College of Technology Sarawak, Persiaran Brooke, 96000 Sibu, Sarawak, Malaysia
}

\begin{abstract}
Petroleum industry produces one of the popular hazardous waste known as Petroleum Sludge. The treatment and disposal of petroleum sludge has created a major challenge in recent years. This review provides insights into various approaches involved in the treatment, and disposal of petroleum sludge. Various methods used in the treatment and disposal of petroleum sludge such as incineration, stabilization/solidification, oxidation, and bio-degradation are explained fully and other techniques utilized in oil recovery from petroleum sludge such as solvent extraction, centrifugation, surfactant EOR, freeze/thaw, pyrolysis, microwave irradiation, electro-kinetic method, ultrasonic irradiation and froth flotation were discussed. The pros and cons of these methods were critically considered and a recommendation for economically useful alternatives to disposal of this unfriendly material was presented.
\end{abstract}

Keywords: Hazardous waste, Petroleum sludge, Sludge disposal, Waste management

\section{Introduction}

In the production and exploration of petroleum, wastes are generated which includes drilling fluid, petroleum wastewater, petroleum effluent treatment plant sludge and bottom tank sludge. A petroleum refinery with a production capability of 105,000 drums per day make approximately 50 tons of oily sludge per year [1]. The remains found at the base of tank and other storage facilities are generally refered to as sludge. For crude oil storage vessels, this kind of sludge found at its base comprises of hydrocarbons, asphaltenes, paraffin, water, and inorganic solids such as sand, iron sulfides and iron oxides. Hydrocarbon is the principal component of petroleum sludge, which is formed when crude oil's properties are changed as a result of changes in external conditions. The formation of petroleum sludge are commonly caused by cooling below the cloud point, evaporation of light ends, mixing with incompatible materials, and the introduction of water to form emulsions [2].

According to Resources Conservation and Recovery Act (RCRA) sludge is separated as a hazardous waste, alongside other hazardous wastes [3]. The elemental composition of petroleum sludge is Nitrogen, Phosphorous, Potassium, Iron, Copper, Calcium, Magnesium, Cadmium, Phosphate, Chromium, Zinc, Sodium, and Lead [4].
Crude oily sludge is a recurrent problem leading to corrosive effects and a reduction in oil storing capacity. The economic effect includes the cost of sludge removal and disposal, where the greater expense is the disposal fee of the environmentally-unfriendly material.

An assortment of methods for processing and disposing of petroleum sludge is used globally, including: thermal, mechanical, biological, and chemical. Altogether, these are not economically sustainable. In summation to the cost of removing, transferring, and land filling involved in cleaning up the petroleum sludge, the sludge also contains several toxic compounds. These contaminants include petroleum hydrocarbons, such as aliphatic hydrocarbons and polycyclic aromatic hydrocarbons (PAHs); over $33 \%$ of total petroleum hydrocarbons (TPH) with $550 \mathrm{mg} / \mathrm{kg}$ of PAHs are present in petroleum oily sludge [5], polychlorinated biphenyls (PCBs), and heavy metals, including barium, lead, zinc, mercury, chromium, arsenic, and nickel [6-8]. Producers, refiners and transporters of petroleum materials should take congnisance of the removal of tank sludge as a very important maintainance practice.

Every storage tanks will accumulate sludge over-time, but petroleum storage tank poses a bigger problems at production locations. Beneficial reuse of petroleum sludge from small production locations necessitates that the sludge material be reused without
This is an Open Access article distributed under the terms of the Creative Commons Attribution Non-Commercial License (http://creativecommons.org/licenses/by-nc/3.0/) which permits unrestricted non-commercial use, distribution, and reproduction in any medium, provided the original work is properly cited.

Copyright (C) 2019 Korean Society of Environmental Engineers
Received April 4, 2018 Accepted August 7, 2018

${ }^{\dagger}$ Corresponding author

Email: O.Johnson@hw.ac.uk

Tel: +60-173847589 Fax: +60-3-8894-3999

ORCID: 0000-0003-0745-880X 
treatment. The use of this waste as a construction material, should prove very economical and environmentally sustainable.

\section{Petroleum Sludge}

Petroleum sludge compositions contain both organic components and heavy metals with typical range of concentrations as reported by the American petroleum institute (API) [9]. According to more recent research works, high concentration of metals in petroleum sludge from refineries was reported as Zn (1,299 mg/kg), Fe $(60,200$ $\mathrm{mg} / \mathrm{kg}$ ), Cu (500 mg/kg), Cr (480 mg/kg), Ni (480 mg/kg), and Pb (565 mg/kg) [10-13].

The improper disposal of petroleum sludge to the environment, create a major threat such as significant modifications in the chemical and physical properties of the surrounding soils, resulting in morphological change [14]. Deficiency in nutrient and stunted growth in the vegetation of receiving soils have been described [15]. The sludge's high viscosity fixes it in soil pores and results in a continuous envelope of the airfoil of the land [16]. Reduction in hygroscopic moisture, hydraulic conductivity, and wetting power of soils have been described in the presence of petroleum sludge $[16,17]$. Elements of high molecular weight have been observed to form hydrophobic crusts thus reducing the availability of water and water-air exchange into the soil [18]. Its long-term effect on farming land have been reported in western Canada [14]. Ineffective treatment and improper disposal of petroleum into the environment is of a major health concern, it contains petroleum hydrocarbons (PHCs) and PAHs that are genotoxic to humans and animals [14]. The PHCs can infiltrate the soil profile into the groundwater, causing a grave menace to the aquatic systems [16, 19]. The presence of PHCs in the soil decreases the diversity of soil microorganisms [17]. The petroleum sludge composition includes a heavy concentrate of PHCs and PAHs. Most of these components are recalcitrant because of their tight molecular bonds, heavy molecular weight, hydrophobicity and little solubility in water.

Proper management of petroleum waste has received greater attention due to increased production and hazardous nature. Several approaches have been prepared to manage it with the aim of bringing down the hazardous contaminant concentration or rendering them motionless, and then as to relieve the environmental and health impact of the unfriendly material. These approaches include, but are not restricted to, the following; landfarming/landfilling, photocatalysis, incineration, solidification/stabilization, solvent extraction, ultrasonic treatment, pyrolysis, chemical handling, and biodegradation [19-24]. Regarding the nature of the hazardous waste, environmental policies and the cost of treatment, but a few of the aforementioned approaches have been successful. Some of the methods employed in recycling hydrocarbons from petroleum sludge are: solvent extraction, centrifugation treatment, surfactant enhanced oil recovery (EOR), frost and melt treatment, sludge pyrolysis, microwave radiation, electromagnetic method, ultrasonic radiation, and froth flotation.

In most of the treatment methods, three phases of waste management technique are used [25], there are (1) reduction of petroleum sludge production through the use of technologies, (2) oil recovery from the oily sludge, and (3) disposal of the unrecoverable petroleum sludge [26, 27]. Stage one helps prevent and reduce petroleum sludge generation, while the other two phases focus on the effective treatment of crude oily sludge.

In this segment we shall survey some of the available treatment techniques and oil recovery methods of petroleum sludge, their advantages and disadvantages will be spotlighted. Various methods utilized in the disposal of petroleum sludge involved Incineration, stabilization/solidification, oxidation, and biodegradation will also be discussed [28].

\subsection{Oil Recovery from Petroleum Sludge}

Equally one of the 3 Rs of sustainability, recycling has proven to be one of the major alternatives to manage petroleum sludge. Recycle is the reprocessing and reformulation of oily sludge with high concentration of oil ( $>50 \%$ ) and a relatively low concentration of solids $(<30 \%)$ by the petroleum industry for energy recovery. Recycling will positively reduce the volume of hazardous petroleum sludge from storage tanks, and therfore preventing environmental pollution and reducing the economic consumption of non-renewable energy resources. In the USA, eighty percent (80\%) of PHCs sludge generated at the refinery are recycled, while the other $20 \%$ was effectively done through approved disposal method [29].

\subsubsection{Solvent extraction}

This is the procedure by which solvent is used at desired proportions to remove non-volatile and semi-volatile organic compounds from ground or water matrices, the oil is separated from the solvent through a distillation process of the mixture [30].

Gazinou et al. [31] investigated the use of turpentine as a solvent for the extraction of petroleum from petroleum sludge, they establish that the recovered oil amounts to about $13-53 \%$ of the initial sludge quantity. Zubaidy and Abouelnasr [22] investigated the impact of methyl ethyl ketone (MEK) and liquefied petroleum gas condensate (LPGC) as an extraction solvent. The outcome indicates that the high oil recovery rate of $39 \%$ can be obtained using MEK while 32\% can be achieved using LPGC at Solvent-to-Sludge ratio of 4:1. Recovered oil by MEK exhibit an improved ash, carbon residue and asphatene levels, though higher levels of sulfur and carbon residue thus requires purification before use.

El Naggar et al. [32] compare different solvents by measuring their extraction effects on dry/semi dry petroleum sludge. Among the solvents tested were naphtha cut, n-heptane, kerosene cut, methylene dichloride, ethylene dichloride, toluene, and diethyl. The results show toluene as the solvent with the highest recovery rate of about seventy-five percent (75.94\%). Morealso Meyer et al. [33] establish that petroleum solvent containing a considerable amount of ring compounds is most effective in dissolving asphaltenic components in petroleum sludge.

Hexane and xylene have also been proven to be an effective recovery, solvent of hydrocarbons from petroleum sludge, recovering up to $67.5 \%$ of PHCs in sludge, mostly in the range of $\mathrm{C}_{9}$ to $\mathrm{C}_{25}$ [34].

Various solvents has been used by different researchers for oily sludge and as reported by El Naggar et al. [32] toluene solvent has proved to be the best and more effective for oily sludge treatment with the highest recovery rate. In summary, solvent extraction is a simple, efficient method of extraction that can be carried out 
in a short period. Nevertheless, when used in a large scale extraction, low efficiency and high variability was reported [35]. It will be necessary to develop some alternative methods to complement solvent extraction in order to improve its performance.

\subsubsection{Centrifugation treatment}

In this method a pre-treated petroleum sludge is drawn through a high-speed rotating equipment with strong centrifugal forces to break up its elements according to their different densities in a short duration. Pre-treatment of the oily sludge is done to reduce it viscosity and thus enhance centrifugation performance and save energy. Some of the pre-treatment method includes the addition of agents such as organic solvents, demulsifying agents and tension active chemicals, the injection of steam, and direct heating [22, 36-38]. Cambiella et al. [37] found that the water-oil separation efficiency of centrifugation can be improved up to $92-96 \%$ with the gain of a modest quantity of a coagulant salt.

Centrifugation treatment process involves mixing the pre-treatment agents with the oily sludge and the mixture is treated in a pre-treatment tank in order to reduce the viscosity. During the centrifugation process the water is separated from the oil (though still containing water and solids), the separated water will be further treated for PHCs removal, while the oil will also be separated from the solids and water to recover the oil using gravimetric separator. All the separated water and solids are further treated in accordance to the environmental standards.

Centrifugation is an advanced clean and efficient method for petroleum sludge treatment. It does not require high energy consumption. However, it requires large space for the installation of the plant, it is very costly and pose environmental concern (noise and pollution) [26, 39].

\subsubsection{Surfactant enhanced oil recovery (EOR)}

This is the process of removing organic pollutants from solid media in a cost effective and fast way, through the application of surfactant. Surfactants are amphiphilic compounds containing both hydrophobic groups as "tails" and hydrophilic groups as "head". It has the ability to lower surface tension or interfacial tension between different types of liquids and between liquids and solids, thus enhance its application in removal of organic pollutants [40]. Example of surfactants that can increase the PHCs concentrations in aqueous phases includes, sodium dodecyi sulphate (SDS), corexit 9527, Triton X-100, Tween 80 and Afonic 1412-7 [41-44].

Abdel-Azim et al. [45] and Dantas et al. [46] investigated the application of three different types of surfactant based on nonyl phenol ethoxylates $(n=9,11,13)$ prepared for study. These were composed of $4 \%$ inorganic acid solution, $10 \%$ of aqueous phase solution composed of NP-9, NP-11 and NP-13 as surfactants and isopropyl or butyl alcohol as co-surfactants and the balance of the system was an oil phase (benzene/toluene, 1:1 mixture). The phase separation period for the mixture was $6 \mathrm{~h}$ and results showed that more than $80 \%$ water can effectively be removed from the sludge. The effect of demulsifier system composition and its concentration in parts per million were observed and was found that the best for complete breakdown of the sludge was the one based on NP-13.

The application of chemical surfactants is fast and cost effective, however, there exist concerns due to environmental toxicity and resistance to biodegradation. Though in the recent times attention has been given to the development of biosurfactant that are more environmentally friendly and biodegradable [41, 47-55].

\subsubsection{Freezing and thawing treatment}

Demulsification is one major method of oil recovery from petroleum sludge, whereby the water is separated from the oil. Freeze/thaw treatment was employed as an effective demulsification process for petroleum sludge in cold regions [56-58].

Freezing and thawing treatment involve two mechanisms for effective demulsification. The first mechanism is when the water phase in the mixture freezes ahead the oil, volume expansion of frozen water droplets result in the coalescence of the water, leading to internal disarrangement of the mixture and then the oil gradually freezes with decrease in temperature. The interfacial tension causes the oil phase to coalesce during the thawing phase resulting in separation of the mixture of oil and water in different phases by gravitational force [59]. In the second mechanism the oil frozen before the water results in the development of a solid cage, thus capturing water droplets during the freezing process. The captured water droplets froze as the temperatures drop thus increasing in volume, the increased volume forces open the oil cage, creating a mixed phase of oil and water that can be separated by gravitational force [59].

Jean et al. [60] discovered that the freeze/thaw process can generate over $50 \%$ of oil from refinery oil-water mixture, whilst Chen and He [56] found that $90 \%$ of water can be separated from a high water content petroleum sludge.

More than $90 \%$ of water were successfully separated from the lubricating oily sludge with application of freezing and thawing method [61]. Lin et al. [58] investigated the effect of four different freezing methods (freezing in a refrigerator, cryogenic bath, dry ice and liquid nitrogen), it was discovered that freezing in cryogenic or dry ice show the best performance of over $70 \%$ dehydration efficiency of a mixture containing $60 \%$ water.

Application of this method will be very well suited for cold regions where natural freezing is possible, though it has its limitation with respect to temperature, duration, water content, salinity of the aqueous phase, presence of surfactant, and solid contents [58].

\subsubsection{Sludge pyrolysis}

The thermal decomposition of organic materials at high temperatures $\left(500-1,000^{\circ} \mathrm{C}\right)$ in an inert environment is called pyrolysis. Hydrocarbons with lower molecular weights are produced during pyrolysis either in condensation (liquid) or non-condensable gases. The end product is always char, liquid, and gases depending on procedural conditions [62, 63]. It was discovered that pyrolysis of oily sludge leads to an increase in oil yield at increased temperature to an optimum temperature of $525^{\circ} \mathrm{C}$, and at a further heating above $525^{\circ} \mathrm{C}$ sees a decrease due to secondary composition as expressed by Shen and Zhang [64]. 80\% of total organic carbon in Petroleum sludge can be converted into usable hydrocarbons using a range of $327-450^{\circ} \mathrm{C}$ pyrolysis as discovered by Liu et al [20]. The proficient separation of oil from sludge happens at 460 to $650^{\circ} \mathrm{C}$ with about 70 to $80 \%$ of the oil separated as revealed by Schmidt and Kaminsky [65]. However the maximum output rate 
of hydrocarbons is at $440^{\circ} \mathrm{C}$ as revealed by Chang et al [66]. Pyrolysis of oily sludge starts at a low temperature of $200^{\circ} \mathrm{C}$ while at 350 to $500^{\circ} \mathrm{C}$, the production of maximum hydrocarbon is achieved with improved oil production as revealed by Wang et al. [67].

Pyrolysis process produces products in fluid phase, making storage and transportation of the recovered oil easy. The recovered oil was also found to share similar qualities and properties with low-grade petroleum distillates from refineries and can be used directly to fuel diesel engines [68, 69]. However, pyrolysis can be limited by various factors, such as temperature, heating rate, characteristics of the sludge and chemical additives. Furthermore, it is not cost effective [70-72], and the product may contain high concentrations of PAHs [73].

\subsubsection{Microwave irradiation}

This process involves the application of microwave frequency in an industrial scale ranging from $900-2,450 \mathrm{MHz}$ [74]. The microwave energy is applied to oily sludge through molecular interaction with the electromagnetic field, resulting in rapid, efficient heating compared with the conventional methods. The heating caused demulsification of the mixture of oil and water, by increasing the temperature of the oil/water mixture thus reducing the viscosity and accelerating the water droplets settlement in the mixtures [75]. The dense hydrocarbons can also be broken by the rapid temperature increase into lighter hydrocarbons. In oily sludge the inner phase is water and it can absorb more microwave energy than oil. The energy absorption in the inner phase of the oil/water mixture results in the expansion of water thus reducing the interfacial film between the water and oil, which could facilitate the separation. The optimum microwave irradiation power and treatment time were $420 \mathrm{~W}$ and $12 \mathrm{~s}$, respectively.

In one investigation, the application of microwave irradiation on 188 barrels of water-oil emulsion gave 146 barrels of oil and 42 barrels of water, with a higher separation efficiency compared to conventional method [76].

Microwave irradiation performance can be limited by factors such as, microwave power, microwave duration, surfactant, $\mathrm{pH}$, salt and some properties of the sludge [77]. Compared to other techniques that involves heating, microwave irradiation can rapily raise the energy of molecules within the medium resulting in higher reaction rates within a very short period of time, which make the method a high energy-efficient. However, it application at industrial-scale is limited because of equipment requirement and high operating cost.

\subsubsection{Electrokinetic method}

This is the process of using direct current (DC) of low-intensity across a pair of electrodes on a permeable medium, resulting in the movement of electron from the lower concentration region to the higher concentration region through the permeable medium in the liquid phase. The respective electrode also enjoy an exchange charged particles of ions and electrophoresis in a colloidal system [78, 79].

Application of electrokinetic method in separation of petroleum sludge is always a three stage mechanism. The first is the breaking down of the colloidal aggregates in the presence of an electrical field that causes migration of colloidal particles of the sludge and solid phase to the anode area (electrophoresis) and the migration of the separated liquid phase in the cathode area (electro-osmosis) [79].

Elektorowicz and Habibi [80] applied electrokinetics in the treatment of oily sludge, the results show that the water content of the sludge can be removed by $63 \%$ and light hydrocarbon by $43 \%$, $50 \%$ of light hydrocarbon was removed when electrokinetic was combined with surfactant.

Though effective, the performance of electrokinetic method can be reduced through various factors such as $\mathrm{pH}$, electrical potential, resistance, and spacing of the electrodes. The application of electrokinetic process for oil recovery from oily sludge compared to other recovery methods such as centrifugation and pyrolysis requires less amount of energy. However, the electrokinetic process studies on oily sludge recovery has only been carried out at the laboratory level, and the performance and cost at a large scale still need further investigation.

\subsubsection{Ultrasonic irradiation}

In this process ultrasonic waves are used to generate compression and rarefactions in the treatment chamber. Ultrasonic irradiation is an effective treatment method of separating solid-liquid in high-concentration suspensions, by decreasing the stability of water-oil mixture [81-84].

During the ultrasonic irradiation process, ultrasonic wave propagates in the treatment medium generates compressions and rarefactions, the compression cycle exerts a positive pressure on the medium by pushing molecules together, while the rarefaction cycle exerts a negative pressures by pulling molecules from each other. The negative pressure thus generate microbubbles, which when grows to an unstable level collapsed violently and cause a shock waves resulting in very high temperature and pressure. The cavitation leads to an increased temperature of the emulsion system and decreased in its viscosity thus enhances mass transfer of the liquid phase, resulting in the destabilization of water-oil mixture [85]. Ultrasonic irradiation is more effective compared to other methods in the sense that it can clean both the solid particle surface and also penetrates into different regions of a multiphase system [86].

$\mathrm{Xu}$ et al. [19] investigated the use of ultrasonic cavitation with a frequency of $28 \mathrm{kHz}$ in oil recovery operation of oily sludge in an ultrasonic cleaning tank; oil separation rate of $55.6 \%$ was reported. They also reported that optimum temperature, acoustic pressure, and the ultrasonic power to be; $40^{\circ} \mathrm{C}, 0.10 \mathrm{MPa}$, and $28 \mathrm{kHz}$, respectively, and that all these factors can affect the oil recovery operation. Zhang et al. [87] found that $80 \%$ oil recovery rate can be achieved from oily sludge-water mixtures within 10 min using ultrasonic irradiation with $20 \mathrm{kHz}$ frequency at a power of $66 \mathrm{~W}$.

Ultrasonic treatment is a highly efficient method without environmental pollution (green treatment), that can be carried out in a very short time. However, factors which include, treatment duration, frequency, water content in the mixture, temperature, solid particle size, initial PHCs concentration, sonication power \& intensity, salinity, and presence of surfactant can limit its performance and it is also very costly method [83, 88, 89].

\subsubsection{Froth flotation}

In this technique, the oil droplets/small solids capturing process 
is achieved through the use of air bubbles in aqueous slurry, the oil droplets/small solids are then floated and collected in a froth layer [90]. In this process, a sludge slurry need to be formed, by adding specified amount of water to the oily sludge. Air is injected to form fine bubbles that meet the oil droplets in the sludge slurry, the decrease and rupture of the water film between the oil droplets and air bubble allows the oil droplets to migrate toward air bubbles, then the mixture of air bubbles and the oil droplets float to the water surface where the accumulated oil can be collected separately for further purification [91].

Ramaswamy et al. [92] found that oil recovery of up to 55\% can be achieved through the application of froth flotation for the treatment of oily sludge at optimum flotation conditions.

Al-Otoon et al. [93] used, modified fluidized flotation process to recover bitumen from sand tar, with $0.35 \mathrm{Wt} \%$ of an extraction solvent; $86 \mathrm{Wt} \%$ of the bitumen was recovered. Stasiuk et al. [94] reported that the surfactant addition in the froth flotation process significantly decreases the water content $(10 \mathrm{v} / \mathrm{v} \%)$ in the oil recovered.

Though effective, froth floatation process can be affected by oily sludge properties (viscosity, solid content, and density), $\mathrm{pH}$, salinity, temperature, air bubble size, presence of surfactant, and treatment duration [95-97].

\section{Petroleum Sludge Disposal Methods}

Disposal methods are applied to petroleum sludge following oil recovery of all useful oil and hydrocarbons. Among various methods used are: incineration, oxidation, solidification/stabilization (S/S), and biodegradation.

\subsection{Incineration}

This is the process by which waste sludge from the petroleum industry undergoes complete combustion in the presence of abundant air and auxiliary fuel. Two major incinerator types used are rotary kiln and fluidized bed. Combustion temperatures in rotary kiln incinerators range between $980-1,200^{\circ} \mathrm{C}$, with a residence time of $30 \mathrm{~min}$, while combustion temperatures in the fluidized bed range between $730-760^{\circ} \mathrm{C}$, with a residence time measured in days [98]. Fluidized bed is best in treatment of sludge with low-quality because of it has high mixing efficiency, fuel flexibility, low pollutant emissions and high combustion efficiency [99].

Sankaran et al. [100] found out that when three types of oily sludge were treated using a fluidized bed incinerator without auxiliary fuels, a high combustion efficiency of 98-99\% was obtained, though the sludge with high content of water must be pre-treated to reduce their viscosity before feeding in the incinerator.

\subsection{Stabilization/Solidification}

$\mathrm{S} / \mathrm{S}$ is a process of encapsulating/ sealing of waste using a binder with the sole aim of preventing the waste leaching into the environment, whether through physical or chemical means and to be able to convert the products to eco-friendly construction materials or non-hazardous waste in the disposal landfill. The $\mathrm{S} / \mathrm{S}$ of hazardous waste by cements involves three major stages:
I . Correcting the chemical contaminants - which involve the chemical interactions between the hydration products of the cement and the contaminants itself.

II. Physically absorbing the contaminants present on the surface of hydrated products of the cements.

III. The encapsulation of contaminated waste or soil (low permeability of the hardened pastes) [101, 102].

In the first and second stages above, it is of most importance to take good note of the nature of the hydration products and the contaminants, because they determine the results while the third stage depends on what sort of hydration products and nature of the pore structure characteristics of the paste. S/S has been globally used in the treatment before disposal of most hazardous waste, low-level radioactive and mixed wastes, as well as remediation of contaminated sites. According to the US Environmental Protection Agency (USEPA), S/S is best Demonstrated Available Technology (BDAT) for 57 hazardous wastes [103]. Of all the binders, hydraulic cements are the most widely used for $\mathrm{S} / \mathrm{S}$ of wastes. The end product can be used for construction purposes depending on the characteristics.

Though S/S is fast and less costly compared to other disposal treatment methods, the release of high concentration organic pollutant is possible when exposed to environmental leachants. Karamaalidis and Voudrias [104] found that in S/S of refinery oily sludge, increased the cement content lead to higher concentration of PAHs and TPH in the leachates.

In the process of improving the ineffectiveness of $\mathrm{S} / \mathrm{S}$ in completely immobilizing the hazardous contaminants, other materials are introduced into the mix. Caldwell et al used activated carbon with Portland cement in the $\mathrm{S} / \mathrm{S}$ treatment or management of organic contaminants and the result showed a significant improvement [105]. Though activated carbon is however costly; a possible cheap material that could combine sorption and binding characteristics is high carbon power plant fly ash (HCFA), a pozzolanic material [106] similar to the PFA widely accepted for use in cement-based construction materials [107], but which contains a higher proportion of unburnt carbon. This carbon may act as a sorbent for organic compounds. Portland cement is often used as a source of alkalinity and calcium to activate pozzolanic reactions in fly ash.

Leonard and Stegemann [108] investigated S/S of waste generated during petroleum exploration and production using Portland cement (CEM1) with incorporation of HCFA as a sorbent for organic contaminants, the result showed that the introduction of HCFA significantly lowered the leaching of PHCs.

In $\mathrm{S} / \mathrm{S}$ treatment of oily sludge the samples were prepared using concrete moulds sealed in plastic bags to prevent possible carbonation due to exposure to air and cured for $24 \mathrm{~h}$ in a humidity chamber with a relative humidity of $98 \pm 2 \%$ and a temperature of $21 \pm 3^{\circ} \mathrm{C}$ before demoulding samples were resealed in plastic bags and transferred back into the humidity chamber for further curing for 7, 28 and $56 \mathrm{~d}$ prior to testing [108].

Asna et al. [109] reported that the introduction of rice husk ash (RHA) at 5,10 , and $15 \%$ as cement substitute material for solidify and stabilize the contaminant of oily sludge as an alternative to reduce the toxicity before final disposal increased the compressive strength of the product from $19.2 \mathrm{~N} / \mathrm{mm}^{2}$ to $24.9 \mathrm{~N} / \mathrm{mm}^{2}$. 


\subsection{Oxidation Treatment}

Oxidation treatment is a degradation process of organic contaminants using chemical and other oxidation agents. In oxidation process reactive agents are introduced into the oily sludge and the organic compound in the oily sludge will be oxidized to carbon dioxide and water or into non-hazardous materials [110]. Various oxidation reagent has been used in this process for oily sludge treatment such as Fenton's reagent, hypochlorite, ozone, ultrasonic irradiation, permanganate, and persulfate. The application of Ultrasonic irradiation on the oily sludge oxidation process has also proven to be effective. During the ultrasonication process which involves the application of sound energy to agitate particles in the oily sludge sample intermediate radicals such as hydrogen $\left(\mathrm{H}^{*}\right)$, hydroxyl $\left(\mathrm{OH}^{*}\right)$, hydroperoxyl $\left(\mathrm{HO}_{2}{ }^{*}\right)$ and hydrogen peroxide $\left(\mathrm{H}_{2} \mathrm{O}_{2}\right)$ will be produced which enhance the breaking down of the complex hydrocarbons into simple hydrocarbons with high solubility.

Mater et al. [21] discovered through their work that a Fenton type reagent can reduce the concentration of PAHs, phenols, and other contaminants in oily sludge contaminated soil at a low $\mathrm{pH}$ of 3.0. Zhang et al. [111] reported that the Fenton oxidation effect on oily sludge degradation could be enhanced by ultrasonic irradiation.

Cui et al. [112] employed supercritical water oxidation (SCWO) method in the treatment of oily sludge; they found that $92 \%$ of chemical oxygen demand (COD) were removed within 10 min into the treatment. They also used wet air oxidation (WAO) in the treatment of oily sludge to effectively remove $88.4 \%$ of COD within $9 \mathrm{~min}$ at temperature of $330^{\circ} \mathrm{C}$ with $\mathrm{O}_{2}$ excess of 0.8 , and this can be improved to $99.7 \%$ COD removal by adding a catalyst.

Oxidation treatment process can be done within a reasonably short period of time on oily sludge, and it can be environmentally friendly (e.g., pollutant loading, temperature change, and the presence of biotoxic substances, etc.) and the end products are biodegradable. However, for large scale application, large amount of chemical reagents may be required, large equipment, increase in energy consumption and invariable high cost of operation.

\subsection{Bioremediation}

The use of microorganisms in the biodegradation and removal of environmental pollutants has been applied to land treatment, bio pile/composting and bio-slurry [113].

\subsubsection{Land farming}

Land farming treatment is a biological, chemical, and physical degradation of oily sludge contaminants by mixing it with soil. Land treatment is more preferable to other disposal methods because of its low cost, low energy consumption, has potential to accommodate large volumes of sludge, and require simple operating procedure [114]. However, it is time consuming and requires a very large area of land; it may not be effective in cold regions.

Marin et al. [115] reported that land farming treatment of oily sludge can remove $80 \%$ of PHCs within 11 mon of treatment in a semi-arid climate, the removal of half of the oily sludge occurred within the first three months.

According to Admon et al. [13] reported that 70-90\% of PHCs degradation can be achieved within 2 mon when land farming treatment was applied to oily sludge; it was observed that most of the degradation occurs within the first 3 weeks of treatment.

Oily sludge land treatment for 12 mon under arid condition was investigated by Hejazi and Husain [116], they observed that tilling (addition of water and nutrients) were the main parameters responsible for the highest PHCs removal in land treatment of oily sludge with a removal rate of $76 \%$.

\subsubsection{Bio pile/composting}

The treatment method whereby petroleum wastes are turned into piles meant for degradation through indigenous or extraneous micro-organisms is known as Bio pile. This treatment technology can replace land treatment which requires large areas of land. This technology is called composting when organic materials are added to improve its efficiency [12].

Wang et al. [117] reported that addition of bulking agent cotton stalk can significantly improve the metabolic microbial activity when composting is employed in the treatment of oily sludge. Liu et al. [118] reported that when manure is added to oily sludge during composting, the microbial activity and diversity increase significantly.

Bio-augmentation using crude manure and straw was found to reduce the TPH content by $46-53 \%$ during the composting of oily sludge within $56 \mathrm{~d}$ in the piles whilst $31 \%$ reduction rate was recorded for control piles [119].

Kriipsalu et al. [120] stated that kitchen waste compost is the most efficient organic material compared to sand amendment, matured oil compost, and shredded waste wood in the reduction of $\mathrm{TPH}$ in oily sludge.

Biopile/composting treatment is environmentally friendly and requires less land space compared to landing farming; however, large area of land is still needed and is also consume more time.

\subsubsection{Bio-slurry treatment}

This method of treatment involves the mixture of sludge-associated solids and water $(5-50 \% \mathrm{w} / \mathrm{v})$, the contaminants is dissolved into the aqueous phase where solubilized pollutants will be obtained in large quantity. Microbial degradation of the pollutants will reduce the toxicity or turn the end product into carbon dioxide and water.

Ayotamuwo et al. [121] reported that a TPH reduction of 40.7-53.2\% can achieved within two weeks and 63.7-85.5\% can be achieved within six weeks in the application of bio-slurry treatment for oily sludge. Ward et al [122] found that up to $80-99 \%$ TPH reduction can be obtained within 10-20 d of oily sludge biodegradation when bio-surfactant was added. Bio-slurry treatment is an effective and fast disposal method for oily sludge and it only requires a small land area, however, it is costly compared to other disposal technologies.

\section{Conclusions}

In the petroleum industry, the generation of oily sludge can not be avoided and this is pose a global challenege in it treatment and management because of it hazardous nature. Several approaches had evolved to effectively manage petroleum sludge, such as; py- 
Table 1. Comparison of Treatment and Disposal Methods of Oily Sludge

\begin{tabular}{|c|c|c|c|c|c|}
\hline Treatment method & $\begin{array}{l}\text { Application } \\
\text { level }\end{array}$ & $\begin{array}{c}\text { Average oil } \\
\text { recovery rate (\%) }\end{array}$ & Advantages & Disadvantages & References \\
\hline Solvent extraction & Field & 70 & Simple, efficient, and save time & $\begin{array}{l}\text { For large scale extraction, low } \\
\text { efficiency and high variability }\end{array}$ & {$[22,30-35]$} \\
\hline Centrifugation & Field & $<50$ & $\begin{array}{l}\text { Clean and efficient, does not } \\
\text { require high energy consumption }\end{array}$ & $\begin{array}{l}\text { Large space for the installation } \\
\text { of the plant, it is very costly and } \\
\text { pose environmental concern }\end{array}$ & $\begin{array}{c}{[22,26,} \\
36-39]\end{array}$ \\
\hline Surfactant EOR & Field & 80 & Fast and cost effective & $\begin{array}{l}\text { Environmental toxicity and } \\
\text { resistance to biodegradation }\end{array}$ & {$[40-55]$} \\
\hline Freeze/thaw & Laboratory & 60 & Suitable for cold regions & $\begin{array}{l}\text { Temperature, duration, high } \\
\text { energy consumption }\end{array}$ & [56-61] \\
\hline Pyrolysis & Field & 70 & Easy and simple & $\begin{array}{l}\text { High energy consumption, high } \\
\text { maintenance and operating cost }\end{array}$ & {$[20,62-73]$} \\
\hline Microwave irradiation & Field & 90 & Fast and efficient & $\begin{array}{l}\text { High energy consumption, high } \\
\text { maintenance and operating cost }\end{array}$ & [74-77] \\
\hline Electrokinetic & Laboratory & 60 & Fast and efficient & $\begin{array}{l}\text { Complicated application and } \\
\text { only in small scale }\end{array}$ & [78-80] \\
\hline Ultrasonic irradiation & Laboratory & 70 & $\begin{array}{l}\text { Fast, highly efficient method } \\
\text { without environmental pollution }\end{array}$ & Very costly & {$[19,81-89]$} \\
\hline Froth flotation & Laboratory & 60 & $\begin{array}{l}\text { Simple application and low } \\
\text { energy consumption }\end{array}$ & Low efficiency & [90-97] \\
\hline Incineration & Field & 90 & Fast and efficient & $\begin{array}{l}\text { High cost of equipment and } \\
\text { environmental pollution }\end{array}$ & [98-100] \\
\hline $\begin{array}{l}\text { Stabilization/ } \\
\text { solidification }\end{array}$ & Laboratory & 90 & Fast and efficient & $\begin{array}{l}\text { Only for oily sludge with low } \\
\text { moisture content(or dry state) } \\
\text { and the end product need } \\
\text { proper management }\end{array}$ & [101-109] \\
\hline Oxidation & Laboratory & 90 & Fast and efficient & $\begin{array}{l}\text { High cost of operation, } \\
\text { environmental pollution }\end{array}$ & {$[21,110-112]$} \\
\hline Land farming & Field & 80 & $\begin{array}{l}\text { Low cost of operation and } \\
\text { support large scale treatment }\end{array}$ & $\begin{array}{l}\text { Slow process, require a very } \\
\text { large portion of land and can } \\
\text { pose environmental concerns }\end{array}$ & {$[13,114-116]$} \\
\hline Biopile/composting & Field & 80 & $\begin{array}{l}\text { Large capacity, fast treatment } \\
\text { than land treatment }\end{array}$ & $\begin{array}{l}\text { High cost of operation and } \\
\text { require land area }\end{array}$ & {$[12,117-120]$} \\
\hline Bioslurry & Field & 90 & $\begin{array}{l}\text { Fast treatment and require small } \\
\text { land area }\end{array}$ & $\begin{array}{l}\text { High cost of operation and } \\
\text { proper management of the end } \\
\text { product }\end{array}$ & {$[121,122]$} \\
\hline
\end{tabular}

rolysis, land farming, ultrasonic treatment, Incineration, $\mathrm{S} / \mathrm{S}$, solvent extraction, photo catalysis, chemical treatment and biodegradation. Table 1 presents the comparisons between various method of treatment and disposal as discussed in this paper, considering the application stage, efficiency, advantages and disadvantages. Some methods are very good in oil recovery but aare associated with high cost of operation and their application at jarge scale may be limited., while others such as landfarming are very simple in application with low cost of operation. However, it will take a very long time (averagely $2 \mathrm{y}$ ) to have a complete treatment of the oily sludge and may also require a large land area.

Since the problems of oily sludge generation is on increase, and most of the treatment methods are quite costly or not effective; ultrasonic treatment, solvent extraction, incineration, and S/S are costly, incineration is also linked with air pollution, whilst land farming and degradation are not effective and associated with leaching of heavy metals, large field of land and time eating up. The selection of the best treatment method may be based various elements such as oily sludge composition, method capacity, costs, and available disposal standard. As such, it may require special decision analysis approaches, to be able to evaluate the overall performance of treatment methods presented in this paper. In the face of all the above stated cons of the treatment and disposal of petroleum sludge, it is imperative to develop a more greener 
and economically viable method to safely dispose this environmentally unfriendly materials.

In conclusion, as the dependency on petroleum products is increasing, which in turn unavoidably lead to increased in the generation of petroleum sludge, it will be indispensable to develop an economically useful alternative to the conventional disposal of petroleum sludge without violating the environment and health safety. Through the development of an innovative disposal approaches and new application of petroleum sludge, its disposal problem can be overcome.

\section{References}

1. Ling CC, Isa $\mathrm{MH}$. Bioremediation of oily sludge contaminated soil by co-composting with sewage sludge. J. Sci. Ind. Res. 2006;65:364-369.

2. Paratene ${ }^{\mathrm{TM}}$ sludge fluidization and recovery [Internet]. [cited 6 November 2017]. Available from: http://www.paratene. com/pdfs/brochures/tanksludgepaper.

3. USEA. Hazardous waste listings - A user-friendly reference document draft [Internet]. c2008 [cited 21 October 2017]. Available from: http://www. epa.gov /osw/hazard/wastetypes/pdfs/listingref.pdf.

4. Asia IO, Enweani IB, Eguavoen IO. Characterization and treatment of sludge. Afr. J. Biotechnol. 2006;5:461-466.

5. Bojes HK, Pope PG. Characterization of EPA's 16 priority pollutant polycyclic aromatic hydrocarbons (PAHs) in tank bottom solids and associated contaminated soils at oil exploration and production sites in Texas, Regul. Toxicol. Pharmacol. 2007;47: 288-295.

6. Neff JM. Composition, environmental, fates, and biological effects of water based drilling muds and cuttings discharged to the marine environment. Prepared for Petroleum Environmental Research Forum and American Petroleum Institute; 2005. p. 1-73.

7. Uko OA. Drill cuttings initiative final report-compilation of reports. Research \& Development Phases 1 and 2, Science Review Group. In: Stakeholder Dialogue Meetings; 2001. p. 1-135.

8. Oljeindustriens Landsforming. Guidelines for characterization of offshore drill cuttings piles. Final Report, Norwegian Oil Industry Association; 2003. p. 1-43.

9. API Environmental Guidance Document: Onshore solid waste management in exploration and production operations. American Petroleum Institute (API), Washington D.C.; 1989. p. $1-120$.

10. da Rocha ORS, Dantas RF, Duarte MMMB, Duarte MML, da Silva VL. Oily sludge treatment by photocatalysis applying black and white light. Chem. Eng. J. 2010;157:80-85.

11. Roldán-Carrillo T, Castorena-Cortés G, Zapata-Pẽnasco I, Reyes-Avila J, Olguín-Lora P. Aerobic biodegradation of sludge with high hydrocarbon content generated by a Mexican natural gas processing facility. J. Environ. Manage. 2012;95:S93-S98.

12. Marín JA, Moreno JL, Hernández T, García C. Bioremediation by composting of heavy oil refinery sludge in semiarid conditions. Biodegradation 2006;17:251-261.
13. Admon S, Green M, Avnimelech Y. Biodegradation kinetics of hydrocarbons in soil during land treatment of oily sludge. Biorem. J. 2001;5:193-209.

14. Robertson SJ, McGill WB, Massicotte HB, Rutherford PM. Petroleum hydrocarbon contamination in boreal forest soils: A mycorrhizal ecosystems perspective. Biol. Rev. 2007;82:213-240.

15. Al-Mutairi N, Bufarsan A, Al-Rukaibi F. Ecorisk evaluation and treatability potential of soils contaminated with petroleum hydrocarbon-based fuels. Chemosphere 2008;74:142-148.

16. Trofimov SY, Rozanova MS. Transformation of soil properties under the impact of oil pollution. Eurasian Soil Sci. 2003;36: S82-S87.

17. Suleimanov RR, Gabbasova IM, Sitdikov RN. Changes in the properties of oily gray forest soil during biological reclamation. Biol. Bull. 2005;32:109-115.

18. Tang J, Lu X, Sun Q, Zhu W. Aging effect of petroleum hydrocarbons in soil under different attenuation conditions. Agr. Ecosyst. Environ. 2012;149:109-117.

19. Xu N, Wang W, Han P, Lu X. Effects of ultrasound on oily sludge deoiling. J. Hazard. Mater. 2009;171:914-917.

20. Liu J, Jiang X, Zhou L, Han X, Cui Z. Pyrolysis treatment of oily sludge andmodel-free kinetics analysis. J. Hazard. Mater. 2009;161:1208-1215.

21. Mater L, Sperb RM, Madureira L, Rosin A, Correa A, Radetski CM. Proposal of a sequential treatment methodology for the safe reuse of oily sludge-contaminated soil. J. Hazard. Mater. B 2006;136:967-971.

22. Zubaidy EAH, Abouelnasr DM. Fuel recovery from waste oily sludge using solvent extraction. Process. Saf. Environ. 2010;88:318-326.

23. Li CT, Lee WJ, Mi HH, Su CC. PAH emission from the incineration of waste oily sludge and PE plastic mixtures. Sci. Total. Environ. 1995;170:171-183.

24. Yan P, Lu M, Yang Q, Zhang HL, Zhang ZZ, Chen R. Oil recovery from refinery oily sludge using a rhamnolipid biosurfactant-producing Pseudomonas. Bioresour. Technol. 2012;116:24-28.

25. Al-Futaisi A, Jamrah A, Yaghi B, Taha R. Assessment of alternative management techniques of tank bottom petroleum sludge in Oman. J. Hazard. Mater. 2007;141:557-564.

26. da Silva VL, Alves FC, de Franc FP. A review of the technological solutions for the treatment of oily sludges from petroleum refineries. Waste Manage. Res. 2012;30:1016-1030.

27. Kriipsalu M, Marques M, Maastik A. Characterization of oily sludge from wastewater treatment plant flocculation-flotation unit in a petroleum refinery and its treatment implications. J. Mater. Cycles Waste Manage. 2008;10:79-86.

28. Hu G, Li J, Zeng G. Recent development in the treatment of only sludge from petroleum industry: A review. J. Hazard. Mater. 2013;261:470-490.

29. Tavassoli T, Mousavi SM, Shojaosadati SA, Salehizadeh H. Asphaltene biodegradation using microorganisms isolated from oil samples. Fuel 2012;93:142-148.

30. Al-Zahrani SM, Putra MD. Used lubricating oil regeneration by various solvent extraction techniques. J. Ind. Eng. Chem. 2013;19:536-539.

31. Gazineu MHP, de Araújo AA, Brandão YB, Hazin CA, Godoy 
JM. Radioactivity concentration in liquid and solid phases of scale and sludge generatedin the petroleum industry. J. Environ. Radioact. 2005;81:47-54.

32. El Naggar AY, Saad EA, Kandil AT, Elmoher HO. Petroleum cuts as solvent extractor for oil recovery from petroleum sludge. J. Petrol. Technol. Altern. Fuel. 2010;1:10-19.

33. Meyer DS, Brons GB, Perry R, Wildemeersch SLA, Kennedy RJ. Oil tank sludge removal method. United States Patent; 2006: US 2006/0042661 A1.

34. Taiwo EA, Otolorin JA. Oil recovery from petroleum sludge by solvent extraction. Petrol. Sci. Technol. 2009;27:836-844.

35. Schwab AP, Su J, Wetzel S, Pekarek S, Banks MK. Extraction of petroleum hydrocarbons from soil by mechanical shaking. Environ. Sci. Technol. 1999;33:1940-1945.

36. Conaway LM. Method for processing oil refining waste. Continuum Environmental, Inc., United States, 1999.

37. Cambiella A, Benito JM, Pazos C, Coca J. Centrifugal separation efficiency in the treatment of waste emulsified oils. Chem. Eng. Res. Des. 2006;84:69-76.

38. Nahmad DG. Method to recover crude oil from sludge or emulsion. United States Patent, US; 2012: 8,197,667 B2.

39. Nii S, Kikumoto S, Tokuyama H. Quantitative approach to ultrasonic emulsion separation. Ultrason. Sonochem. 2009;16:145-149.

40. Mulligan CN. Recent advances in the environmental applications of biosurfactants. Curr. Opin. Colloid Interface Sci. 2009;14:372-378.

41. Christofi N, Ivshina IB. A review: Microbial surfactants and their use in fieldstudies of soil remediation. J. Appl. Microbiol. 2002;93:915-929.

42. Grasso D, Subramaniam K, Pignatello JJ, Yang Y, Ratte D. Micellar desorption of polynuclear aromatic hydrocarbons from contaminated soil. Colloids Surf. A 2001;194:65-74.

43. Cuypers C, Pancras T, Grotenhuis T, Rulkens W. The estimation of PAH bioavailability in contaminated sediments using hydroxypropyl-beta-cyclodextrin and Triton X-100 extraction techniques. Chemosphere 2002;46:1235-1245.

44. Prak DJL, Pritchard PH. Degradation of polycyclic aromatic hydrocarbons dissolved in Tween 80 surfactant solutions by Sphingomonas paucimobilis EPA 505. Can. J. Microbiol. 2002;48:151-158.

45. Abdel-Azim AA, Abdul-Raheim AM, Kamel RK, Abdel-Raouf ME. Demulsifier systems applied to breakdown petroleum sludge. J. Petrol. Sci. Eng. 2011;78:364-370.

46. de Castro Dantas TN, Neto AAD, Moura EF. Microemulsion systems applied to breakdown petroleum emulsions. J. Petrol. Sci. Eng. 2001;32:145-149.

47. Mulligan CN, Yong RN, Gibbs BF. Surfactant-enhanced remediation of contaminated soil: A review. Eng. Geol. 2001;60:371-380.

48. Whang LM, Liu PW, Ma CC, Cheng SS. Application of biosurfactants, rhamnolipid, and surfactin, for enhanced biodegradation of diesel-contaminated water and soil. J. Hazard. Mater. 2008;151:155-163.

49. Cort TL, Song MS, Bielefeldt AR. Nonionic surfactant effects on pentachlorophenol degradation. Water Res. 2002;36:1253-1261.

50. Syal S, Ramamurthy V. Characterization of biosurfactant synthesis in a hydrocarbon utilizing bacterial isolate. Indian $J$.
Microbiol. 2003;43:175-180.

51. Urum K, Pekdemir T. Evaluation of biosurfactants for crude oil contaminated soil washing. Chemosphere 2004;57:1139-1150.

52. Ron EZ, Rosenberg E. Biosurfactants and oil bioremediation. Curr. Opin. Biotechnol. 2002;13:249-252.

53. Mulligan CN. Environmental applications for biosurfactants. Environ. Pollut. 2005;133:183-198.

54. Pekdemir T, Copur M, Urum K. Emulsification of crude oil-water system using biosurfactant. Process. Saf. Environ. 2005;83:38-46.

55. Chin CL, Yi CH, Yu HW, Jo SC. Biosurfactant-enhanced removal of total petroleum hydrocarbons from contaminated soil. J. Hazard. Mater. 2009;167:609-614.

56. Chen GH, He GH. Separation of water and oil from water-in-oil emulsion by freeze/thaw method. Sep. Purif. Technol. 2003;31: 83-89.

57. Sean DS, Lee DJ. Expression deliquoring of oily sludge from a petroleum refinery plant. Waste Manage. 1999;19:349-354.

58. Lin G, He G, Li X, et al. Freeze/thaw induced demulsification of water-in-oil emulsions with loosely packed droplets. Sep. Purif. Technol. 2007;56:175-183.

59. Lin C, He G, Dong C, Liu H, Xiao G, Liu Y. Effect of oil phase transition on freeze/thaw-induced demulsification of water-in-oil emulsions. Langmuir 2008;24:5291-5298.

60. Jean DS, Lee DJ, Wu JSU. Separation of oil from oily sludge by freezing and thawing. Water Res. 1999;33:1756-1759.

61. He G, Chen G. Lubricating oily sludge and its demulsification. Dry. Technol. 2002;20:1009-1018.

62. Fonts I, Gea G, Azuara M, Ábrego J, Arauzo J. Sewage sludge pyrolysis for liquid production: A review. Renew. Sust. Energ. Rev. 2012;16:2781-2805.

63. Zhang SP, Yan YJ, Li YC, Ren ZW. Upgrading of liquid fuel from the pyrolysis of biomass. Bioresour. Technol. 2005;96:545-550.

64. Shen L, Zhang DK. An experimental study of oil recovery from sewage sludge by low-temperature pyrolysis in a fluidised-bed. Fuel 2003;82:465-472.

65. Schmidt H, Kaminsky W. Pyrolysis of oily sludge in a fluidised bed reactor. Chemosphere 2001;45:285-290.

66. Chang CY, Shie JL, Lin JP, Wu CH, Lee DJ, Chang CF. Major products obtained from the pyrolysis of oily sludge. Energ. Fuel. 2000:14;1176-1183.

67. Wang Z, Guo Q, Liu X, Cao C. Low temperature pyrolysis characteristics of oily sludge under various heating conditions. Energ. Fuel. 2007;21:957-962.

68. Czernik S, Bridgwater AV. Overview of applications of biomass fast pyrolysis oil. Energ. Fuel. 2004;18:590-598.

69. Chiaramonti D, Oasmaa A, Solantausta Y. Power generation using fast pyrolysis liquids from biomass. Renew. Sust. Energ. Rev. 2007;11:1056-1086.

70. Bridle TR, Pritchard R. Energy and nutrient recovery from sewage sludge via pyrolysis. Water Sci. Technol. 2004;50:169-175.

71. Kim Y, Parker. A technical and economic evaluation of the pyrolysis of sewage sludge for the production of bio-oil. Bioresour. Technol. 2008;99:1409-1416.

72. Bridle T, Unkovich I. Critical factors for sludge pyrolysis in Austrilia. Water 2002;29:43-48.

73. Kwah TH, Maken S, Lee JW, Park BR, Min BR, Yoo YD. Environmental aspects of gasification of Korean municipal solid 
waste in a pilot plant. Fuel 2006;85:2012-2017.

74. Appleton TJ, Colder RI, Kingman S, Lowndes IS, Read AG. Microwave technology for energy-efficient processing of waste. Appl. Energ. 2005;81:85-113.

75. Tan W, Yang X, Tan X. Study on demulsification of crude oil emulsions by microwave chemical method. Sep. Sci. Technol. 2007;42:1367-1377.

76. Fang CS, Lai PMC. Microwave heating and separation of water-in-oil emulsion. J. Microw. Power Electrom. Energ. 1995;30: 46-57.

77. Fortuny M, Oliveira CBZ, Melo RLFV, Nele M, Coutinho RCC, Santo AF. Effect of salinity, temperature, water content, and $\mathrm{pH}$ on the microwave demulsification of crude oil emulsion. Energ. Fuel. 2007;21:1358-1364.

78. Kuo CH, Lee CL. Treatment of oil/water emulsions using seawater-assisted microwave irradiation. Sep. Purif. Technol. 2010;74:288-293.

79. Yang L, Nakhla G, Bassi A. Electro-kinetic dewatering of oily sludges. J. Hazard. Mater. 2005;125:130-140.

80. Elektorowicz M, Habibi S. Sustaibable waste management: Recovery of fuels from petroleum sludge. Can. J. Civil. Eng. 2005;32:164-169.

81. Li J, Song X, Hu G, Thring RW. Ultrasonic desorption of petroleum hydrocarbons from crude oil contaminated soils. J. Environ. Sci. Health A 2013;8:1378-1389.

82. Song W, Li J, Zhang W, Hu X, Wang L. An experimental study on the remediation of phenanthrene in soil using ultrasound and soil washing. Environ. Earth Sci. 2012;66:1487-1496.

83. Kim YU, Wang MC. Effect of ultrasound on oil removal from solids. Ultrason. Sonochem. 2003;41:539-542.

84. Ye G, Lu X, Han P, Peng F, Wang Y, Shen X. Application of ultrasound oncrude oil pretreatment. Chem. Eng. Process. 2008; $47: 2346-2350$.

85. Chung HI, Kamon M. Ultrasonically enhanced electrokinetic remediation for removal of $\mathrm{Pb}$ and phenanthrene in contaminated soils. Eng. Geol. 2005;77:233-242.

86. Swamy KM, Narayana KL. Intensification of leaching process by dual-frequency ultrasound. Ultrason. Sonochem. 2001;8:341-346.

87. Zhang J, Li JB, Thring RW, Hu X, Song XY. Oil recovery from refinery oily sludge via ultrasound and freeze/thaw. J. Hazard. Mater. 2012;203-204:195-203.

88. Feng D, Aldrich C. Sonochemical treatment of simulated soil contaminated with diesel. Adv. Environ. Res. 2000;4:103-112.

89. Na S, Park Y, Hwang A, Ha J, Kim Y, Khim J. Effect of ultrasound on surfactant-aided soil washing. JPN. J. Appl. Phys. 2007;46:4775-4778.

90. Canselier JP, Delmas H, Wilhelm AM, Abismaïl B. Ultrasound emulsification - An overview. J. Disper. Sci. Technol. 2007;23:333-349.

91. Moosai R, Dawe RA. Gas attachment of oil droplets for gas flotation for oily wastewater cleanup. Sep. Purif. Technol. 2003;33:303-314.

92. Ramaswamy D, Kar DD, De S. A study on recovery of oil from sludge containing oil using froth flotation. J. Environ. Manage. 2007;85:150-154.

93. Al-Otoom A, Allawzi M, Al-Omari N, Al-Hsienat E. Bitumen recovery from Jordanian oil sand by froth flotation using petroleum cycles oil cuts. Energy 2010;35:4217-4225.

94. Stasiuk EN, Schramm LL. The influence of solvent and demulsifier additions on nascent froth formation during flotation recovery of Bitumen from Athabasca oil sands. Fuel Process. Technol. 2001;73:95-110.

95. Al-Shamrani AA, James A, Xiao H. Separation of oil from water by dissolved air flotation. Colloids Surf. A 2002;209:15-26.

96. Faksness LG, Grini PG, Daling PS. Partitioning of semi-soluble organic compounds between the water phase and oil droplets in produced water. Mar. Pollut. Bull. 2004;48:731-742.

97. Guo SH, Li G, Qu JH, Liu XL. Improvement of acidification on dewaterability of oily sludge from flotation. Chem. Eng. J. 2011;168:746-751.

98. Scala F, Chirone R. Fluidized bed combustion of alternative solid fuels. Exp. Therm. Fluid. Sci. 2004;28:691-699.

99. Zhou L, Jiang X, Liu J. Characteristics of oily sludge combustion in circulating fluidized beds. J. Hazard. Mater. 2009;170:175-179.

100. Sankaran S, Pandey S, Sumathy K. Experimental investigation on waste heatrecovery by refinery oily sludge incineration using fluidised-bed technique. J. Environ. Sci. Health. A 1998;33:829-845.

101. Shi C, Day RL, Wu X, Tang M. Uptake of metal ions by autoclaved cement pastes. In: Proceedings of Materials Research Society, vol. 245, Materials Research Society, Boston; 1992. p. 141-149.

102. Shi C, Shen X, Wu X, Tang M. Immobilization of radioactive wastes with portland and alkali-slag cement pastes. Il Cemento 1994;91:97-108.

103. USEPA. Technology resource document - Solidification/stabilization and its application to waste materials. USEPA, June 1993 (EPA/530/R-93/012).

104. Karamalidis AK, Voudrias EA. Cement-based stabilization/solidification of oil refinery sludge: Leaching behavior of alkanes and PAHs. J. Hazard. Mater. 2007;148:122-135.

105. Poon CS, Qiao XC, Lin ZS. Pozzolanic properties of reject fly ash in blended cements pastes. Cement Concrete Res. 2003;33:1857-1865.

106. Sear LKA. Should you be using more PFA? In: Dundee University Conference, Global Construction, Ultimate Concrete Opportunities; 2005.

107. Caldwell RJ, Cote P, Chao CC. Investigation of solidification for the immobilization of trace organics contaminants. Hazard. Waste Hazard. Mater. 1990;7:273-281.

108. Leonard SA, Stegemann JA. Stabilization/solidification of petroleum drill cuttings. J. Hazard. Mater. 2010;174:463-472.

109. Asna MZ, Md GS, Hilmi M. Immobilization of petroleum sludge incorporating portland cement and rice husk ash. Int. J. Chem. Eng. Appl. 2010;1:234-240.

110. Ferrarese E, Andreottola G, Oprea IA. Remediation of PAH-contaminated sediments by chemical oxidation. J. Hazard. Mater. 2008;152:128-139.

111. Zhang J. Treatment of refinery oily sludge using ultrasound, bio-surfactant,and advanced oxidation processes [M.Sc. thesis]. Prince George: Univ. of Northern British Columbia; 2012.

112. Cui B, Cui F, Jing G, Xu S, Huo W, Liu S. Oxidation of oily sludge in supercritical water. J. Hazard. Mater. 2009;165:511-517. 
113. Powell SM, Paul M, Harvey PM, Stark SJ, Snipe I, Riddle JM. Biodegradation of petroleum products in experimental plots in Antarctic marine sediments is location dependent. Mar. Pollut. Bull. 2007;54:434-440.

114. Khan FI, Husain T, Hejazi R. An overview and analysis of site remediation technologies. J. Environ. Manage. 2004;71: 95-122.

115. Marín JA, Hernández T, García C. Bioremediation of oil refinery sludge by landfarming in semiarid conditions: Influence on soil microbial activity. Environ. Res. 2005;98:185-195.

116. Hejazi RF, Husain T. Landfarm performance under arid conditions. 2. Evaluation of parameters. Environ. Sci. Technol. 2004;38:2457-2469.

117. Wang X, Wang QH, Wang SJ, Li FS, Guo GL. Effect of biostimulation on community level physiological profiles of microorganisms in field-scale biopiles composed of aged oily sludge. Bioresour. Technol. 2012;111:308-315.
118. Liu WX, Luo YM, Teng Y, Li ZG, Ma LQ. Bioremediation of oily sludge-contaminated soil by stimulating indigenous microbes. Environ. Geochem. Health 2010;32:23-29.

119. Ouyang W, Liu H, Murygina V, Yu YY, Xiu ZD, Kalyuzhnyi $\mathrm{S}$. Comparison of bio-augmentation and composting for remediation of oily sludge: A field-scale in China. Process. Biochem. 2005;40:3763-3768.

120. Kriipsalu M, Marques M, Nammari DR, Hogland W. Biotreatment of oily sludge: The contribution of amendment material to the content of target contaminants, and the biodegradation dynamics. J. Hazard. Mater. 2007;148:616-622.

121. Ayotamuno MJ, Okparanma RN, Nweneka EK, Ogaji SOT, Probert SD. Bioremediation of a sludge containing hydrocarbons. Appl. Energ. 2007;84:936-943.

122. Ward O, Singh A, van Hamme J. Accelerated biodegradation of petroleum hydrocarbon waste. J. Ind. Microbiol. Biotechnol. 2003;30:260-270. 